our case-control study could not find any evidence that the patient population undergoing dialysis in the unit had changed between 1995 and 1996. The decline in the bacteremia rate in June 1996 was associated with only slight reduction in CVC use and was only transient. Because this transient decline occurred at a time when multiple educational interventions occurred, we believe these to have accounted for the decline. Subsequent to this study, the dialysis bacteremia rate has remained largely stable, at approximately twice the historical rate, and the CVC use remains approximately $40 \%$.

For these reasons, we believe that the rise in hemodialysis-related bacteremia in our unit is attributable to increased use of CVCs for vascular access, which in turn was due to changes in healthcare delivery in our region that have resulted in delays in creation of vascular grafts for hemodialysis access.

Health care in our region, as elsewhere in North America, is undergoing radical redesign. While planning is involved, the ultimate effect of any change process cannot be predicted with certainty. There is evidence that the structure of healthcare delivery, for example the nurse-to-patient ratio, can affect the rate at which nosocomial infections occur. ${ }^{10,11}$ In our case, it appears that a series of changes in the regional public healthcare system led to increased dialysis-related bacteremia, a result that would have been difficult to predict in advance. As health care across North America continues to be restructured, nosocomial infection rates may provide one reliable measure of the impact of changed processes of care delivery.

\section{REFERENCES}

1. Churchill DN, Taylor DW, Cook RJ, LaPlante P, Paul B, Cartier P, et al. Canadian hemodialysis morbidity study. Am J Kidney Dis 1992;19: 214-234.

2. Chow JW, Sorkin M, Goetz A, Yu VL. Staphylococcal infections in the hemodialysis unit: prevention using infection control principles. Infect Control Hosp Epidemiol 1988;9:531-533.

3. Johnson WJ, Kurtz SB, Mitchell JC III, Van Den Berg CJ, Wochos DN, O'Fallon W, et al. Results of treatment of center hemodialysis patients. Mayo Clin Proc 1984;59:669-671.

4. Hoen B, Kessler M, Hestin D, Mayeux D. Risk factors for bacterial infections in chronic hemodialysis adult patients: a multicentre prospective survey. Nephrol Dial Transplant 1995;10:377-381.

5. Cheesbrough JS, Finch RG, Burden RP. A prospective study of the mechanisms of infection associated with hemodialysis catheters. J Infect Dis 1986;154:579-589.

6. Capital Health Annual Report, 1995/96. Edmonton, Alberta, Canada: Capital Health Authority; 1996.

7. Garner JS, Jarvis WR, Emori TG, Horan TC, Hughes JM. CDC definitions for nosocomial infections, 1988. Am J Infect Control 1988;16:128140

8. Pignatari A, Boyken LD, Herwaldt LA, Hollis R, Leme I, Sesso R, et al. Application of restriction endonuclease analysis of chromosomal DNA in the study of Staphylococcus aureus colonization in continuous ambulatory peritoneal dialysis patients. Diagn Microbiol Infect Dis 1992;15:195199

9. Goh SH, Byrne S, Zhang JL, Chow AW, Molecular typing of S aureus on the basis of coagulase gene polymorphisms. J Clin Microbiol 1992;30:1642-1645

10. Fridkin SK, Pear SM, Williamson TH, Galgiani JN, Jarvis WR. The role of understaffing in central venous catheter-associated bloodstream infections. Infect Control Hosp Epidemiol 1996;17:150-158.

11. Haley RP, Bergman DA. The role of understaffing and over-crowding in recurrent outbreaks of staphylococcal infection in a neonatal specialcare unit. J Infect Dis 1982;145:875-885.

\title{
Stenotrophomonas maltophilia and Cystic Fibrosis
}

\section{Gina Pugliese, RN, MS} Martin S. Favero, PhD

Infections caused by Stenotrophomonas maltophilia in patients with cystic fibrosis have been the subject of many studies, and the role of the environment has been puzzling. Denton and coinvestigators from St James's University Hospital, Leeds, United Kingdom, conducted a study on this subject. $S$ maltophilia was isolated from the respiratory tracts of 41 (25\%) of 163 children attending a pediatric cystic fibrosis unit between September 1993 and December 1995. The extent of $S$ maltophilia contamination of environmental sites frequented by these patients were investigated with a selective medium incorporating vancomycin, imipenem, and amphotericin B.

Cultures of eighty-two isolates of $S$ maltophilia were obtained from 67 differ- ent environmental sites sampled between January and July 1996. The organism was widespread in the home environment, with $20(36 \%)$ and $25(42 \%)$ of sampled sites positive in the homes of colonized and noncolonized patients, respectively. In the hospital setting, it was isolated from $18(32 \%)$ sites in the hospital ward and from 4 (17\%) sites in the outpatient-clinic area. The most common sites of contamination were sink drains, faucets, and other items frequently in contact with water. All environmental and clinical isolates were genotyped with enterobacterial repetitive intergenic consensus sequences as primers.

A total of 33 of the 41 patients were colonized with unique strains, and four pairs of patients shared strains. Further characterization by pulsed-field gel electrophoresis after digestion with $X b a \mathrm{I}$ found that there was no evidence of patient-to-patient transmission; however, there was some evidence that a small number of patients may have acquired the organism from the hospital environment. Resampling of environmental sites in the hospital ward in January 1997 revealed evidence of genetic drift, complicating the accurate determination of environmental sources for clinical strains.

The source of the majority of $S$ maltophilia strains colonizing the respiratory tracts of these patients with cystic fibrosis remained uncertain but may have represented multiple, independent acquisitions from a variety of environmental sites both within and outside the hospital.

FROM: Denton M, Todd NJ, Kerr KG, Hawkey PM, Littlewood JM. Molecular epidemiology of Stenotrophomonas maltophilia isolated from clinical specimens from patients with cystic fibrosis and associated environmental samples. J Clin Microbiol 1998;36:1953-1958. 